\title{
SMART REGIONAL SPECIALIZATION - OPPORTUNITY OR OXYMORON OF THE DEVELOPMENT OF SMALL AND MEDIUM ENTERPRISES
}

\author{
Desislava Botseva ${ }^{1}$ \\ Georgi Tsolov ${ }^{2}$ \\ Nikola Tanakov ${ }^{3}$
}

DOI: https://doi.org/10.31410/LIMEN.2020.121

\begin{abstract}
The need to understand and characterize management approaches, especially in their modern context, is becoming particularly important, mostly to test small and mediumsized businesses' ability to adapt to modernization's high demands. According to the research team, several challenges generated by various constraints, external and internal to organizations of this type, are why they fail to reach their growth and development potential. However, such a statement must be a subjected to a severe analysis based on the methodology of a new, modern system of indicators to illustrate SMEs' real readiness and ability to be in line with development trends. The regional sector analysis successfully identifies the prerequisites for these enterprises' development and determines their specific regional potentials. The study analyzes the small and medium-sized enterprise sector in the Balkan countries and within the European Union. The research team identifies the predisposition for small and medium enterprises to regional specialization, application of innovations, technologies, entrepreneurial discoveries, digitalization and strategy, planning, and programming of a new generation.
\end{abstract}

Keywords: Regional specialization, Smart specialization, SMEs, Innovation, Regional competitiveness.

\section{INTRODUCTION}

$\mathrm{T}$

The continuous and contemporary discussion on small and medium-sized enterprises (SMEs) remains to excite and arouse research interest in the present. Of particular importance is the sector's study to consider its fundamental role in the process of development, updating, and modernizing the sectors of national economies. Today, the need to analyze and evaluate the SME sector's development is more critical than ever. We can observe the reasons in two particular aspects. First, there is a need to study SMEs' value and their importance for developing the socio-economic nature of the regions. Second, how does this development improve SMEs' ability to modernize their activities to provide an adequate response to societies' continuous and dynamic modernization? Many authors and researchers on the topic of SMEs support the thesis that these structures have, to no small extent, an unrealized potential that should be exploited, especially in the context of modernity, shaped by the economy 4.0 and society 5.0 (Nikolov, G. 2019). Such a formulation should be subjected to an analysis based on a new methodology and a modern system of indicators to illustrate SMEs' real readiness to adapt to modern development challenges and trends. In turn, such

University of National and World Economy, Student Town, 1700 Sofia, Bulgaria

University of National and World Economy, Student Town, 1700 Sofia, Bulgaria

University of National and World Economy, Student Town, 1700 Sofia, Bulgaria 
development must be considered and characterized from different positions, economic, social, technical and technological, informational, infrastructural, cultural, and many others, presenting the modern picture of regional development's integrity, designed to engage all these aspects.

The management of small and medium-sized enterprises (SMEs) in the structures of national economies has always been a topic of discussion, which arouses serious research interest.

The research team observes this statement from two opposing positions. First, through analysis and empirical verification, to characterize SME management's importance as an opportunity to increase their usefulness for a territory's economic development. Second, to what extent, the achieved development and specialization of the territory (region) promote the progress of SMEs in such a way that they, in their activities, can optimally respond to the rise of modern societies and new concepts related to globalization, digitalization, economy 4.0 and society 5.0. There is hardly a researcher on the development and management of small and mediumsized businesses that supports the claim that these structures make optimal use of their capabilities. In turn, we consider and characterize such development must by different positions, economic, social, technical and technological, informational, infrastructural, cultural, access to finance, innovation, and many others, presenting the modern picture of regional development's integrity engage all these aspects. The author's team will identify the predisposition of small and medium businesses to regional specialization, application of innovations, technologies, entrepreneurial discoveries, digitalization and strategy, planning, and programming of a new generation.

One of the possibilities to research the SME sector and their condition is their regional sector analysis. It creates good preconditions for identifying the development factors of these enterprises and could determine their specific regional potentials. The use of the regional sector analysis of SMEs enables decision-making and implementation of mechanisms to support specific sectors of the economy and thus ensure their success. From another point of view, it is essential to assess the effect of these interventions on the economies of the countries and their impact on the development of the region in which the incentives applied to SMEs operate. The authors of the present study support the hypothesis that there is an objective need for timely assessment of such interventions and their impact on the development of both the SME sector and the specific industry to which they belong, and the overall development of the region. These mechanisms should aim to achieve a multiplier effect by generating added value, stimulating export activity, and increasing employment.

\section{A BRIEF OVERVIEW OF REGIONAL SPECIALIZATION THEORIES EVOLUTION}

At the dawn of the emergence of regional economic literature, most economists believe that differences in their size determine individual territories' wealth. This economic thought line has been called "mercantilism" developed by European Scholars T. Moon, W. Petty, J.W. Colbert in the late 16th and 17th centuries. Mercantilists maintain the view that the amount of gold and silver determines the wealth of the territory. They suggest that the interventions related to the territories' economic development should aim at increasing them. To achieve this, they propose to stimulate the exports and restrict imports, except exports of precious metals.

Thus, recognizing the vital role of trade for economic growth is accompanied by an increase in restrictions and strict foreign exchange regulation by the state. One of the first British 
representatives of classical economic theory, Adam Smith (1789), criticized these limitations. He showed that the territory well-being depends not on the amount of gold and silver as on the production level through the division of labor and cooperation. He supports the view that the region's specialization must be based on the principle of absolute advantage. The region exports its products at the lowest price and imports those made in other lower-cost areas. Producers must operate in conditions of free competition and a certain amount of economic freedom. Thus, was born the theory of absolute advantage.

The absolute advantage theory has clearly shown how foreign trade should occur if there is an absolute advantage in the region. However, it does not answer how a region can participate in foreign trade areas if it does not have such an "absolute advantage." The theory of "comparative advantage" derived the answer to that question. Another representative of the classical school, David Ricardo (1817), developed the theory of absolute advantages and showed that trade could be mutually beneficial, even if one of the regions did not have an absolute advantage in producing certain products or services. Ricardo, who essentially developed A. Smith's theory proved that absolute advantages are only a particular case of the principle of rational division of labor, based not on absolute but relative (comparative) advantages. Even countries (regions) with higher production costs for their products can benefit from specialization in foreign markets due to the difference in prices between different participants. The comparative advantage principle is that the regions must specialize in the production of those goods that they can sell at the lowest comparative cost compared to other regions. Comparative costs show how much of the production of some goods we have to give up to increase the production of others by one.

In the theories of Adam Smith and David Ricardo, the main factor in determining the rational structure of production and exchange is labor costs, in the 30s of the XX century. Swedish economists E. Heckscher and B. Olin (1992) developed a theory of international (interregional) division of labor, taking into account the ratio of the main interchangeable factors of production (labor, land, capital, etc.). From Heckscher and Olin's conclusions, it is clear that backward or developing countries (regions), which as a rule have an intense shortage of capital and surplus labor, must specialize in the production and export of labor-intensive products. Developed countries and regions with accumulated significant capital (including scientific and technical) must strive to export capital-intensive products. The natural-geographical profile of the territory strongly influences the specialization. Thus, e.g., countries and regions with sizeable agricultural land areas and relatively low population density should expand agricultural exports. Land and other natural resources are immovable factors, and only the products of their exploitation can move.

The key assumptions and interpretations of the Heckscher-Olin theory are tested and corrected in the coming decades. In particular, this was done to search for relevant export and import patterns of goods, taking into account the direct costs of the production factors and the indirect ones, concentrated in raw materials and consumables. This analytical task was realized much later. In the late 1940s, Vasily Leontiev subjected the theory to empirical verification. The results of this inspection went down in history as Leontief's paradox. Leontiev decided to check whether since capital is abundant in the United States, based on a comparison with other partner countries, the country's exports are mainly capital-intensive goods and imports of laborintensive ones. Among the calculations and comparison of the results obtained, it turned out that US imports are more capital-intensive than exports. 
There is a lot of research in the regional economic literature that has approached regional specialization and concentration problems. The definitions of regional specialization are based on the same production structures, reflecting the same reality. Regional specialization expresses the territorial perspective and depicts the distribution of sectoral shares in one region, usually compared to the rest of the country. Here, localization theories play a significant role in shaping the theoretical foundation.

The creation of the theory of the location of objects is associated with the publication (in 1826) of the book by the German economist J. Thünen "The isolated state in terms of agriculture and the national economy" (Der isolierte Staatin Beriehung auf Landwirshaft und National Okonomie). The theory is based on the assumption that there is an economically isolated country in the world. There is a single central city, the only market for agricultural products, and a source of industrial goods (The theory of location of agricultural products). The method which compares the costs of delivery and transport of goods from the production point to the market (city) should be used. As a result of the analysis, it determines the most favorable areas for the positioning of individual types of agricultural products (their specialization). Despite von Thünen's work (since in practice, no state meets the prerequisites set in his theory), it becomes a critical example of the use of mathematical models in the view of spatial economics. The modern economy appreciates and recognizes its essential methodological significance and value.

The next step in developing localization theories was made with the advent of ideas about industrial objects of economic activity. W. Laundhart and A. Weber are recognized as founders of this trend. W. Laundhart developed a theory for the rational localization of industrial enterprises. Its most important achievement is the method of finding the optimal location for the location of a unit of an industrial enterprise in terms of sources of raw materials and markets for the sale of products. The determining factor in both Johann von Thünen's Theory and Wilhelm Launhard's Theory is transport costs. Laoundhart's views are further developed in the works of A. Weber. The most significant works of the German economist and sociologist Alfred Weber are "Theory of the location of industry (1904)" and "Theory of the location of industry. Pure Standard Theory (1909)". They become the most circumstantial theories in this area.

Afterwards, the next stage of the localization theories development is the emergence of the socalled settlement positioning theory. W. Kristaler introduced the first functional Theory related to the localization of settlements in the market system. His central places theory was revealed in the work Central Places in Southern Germany, published in 1913.

The general spatial theory was developed in the twentieth century. Its author is A. Lösch, a Polish economist whose views are set out in his work "Spatial Organization of the Economic," published in 1940. The general spatial theory is linked to the private ideas of Thünen, Weber, Kristaler. We can conclude that he is the founder of the thinking for the specialization of regional industries because he set himself the task to justify the possibility of the rational geographical distribution of production. His book indicates the most advantageous options for the location of newly built industrial enterprises in the centers with active economic life and in the market areas. Lösch bases his scientific work on the subject of localization theory, moving from the development of enterprises and the community to the problems of forming economic regions. The most important contribution of A. Lösch is developing the basic principles of spatial theory and financial equilibrium. 
From all the above, we can conclude that regional specialization expresses the local perspective and depicts the distribution of sectoral shares in the regional economy, usually compared to the rest of the country. A region is considered highly specialized if a small number of industries have a large share in that region's economy.

\section{REGIONAL OR SECTORAL SPECIALIZATION FOR SMES IN BULGARIA, SOME BALKAN COUNTRIES AND THE EU}

The small and medium-sized enterprise sector forms the largest segment of enterprises in the national economies of both the Balkan countries and the European Union. There are cases in the Balkans and the EU, where over $99 \%$ of all enterprises are small or medium-sized. For example, in the Bulgarian economy, they form $99.8 \%$ representation in the country's economic structure. We could note that they generate more than $65 \%$ of value-added and more than $75 \%$ of employment. According to the indicators, the country is significantly ahead of the average Union's values (over ten percentage points) - Current data on SMEs (2014-2018), Ministry of Economy of the Republic of Bulgaria. However, this is not the case when considering the average indicator productivity of Bulgarian SMEs, which is still significantly behind the Union's average values. That is why increasing the competitiveness of SMEs is key to the Bulgarian and Balkan country's economic development. For example, the case in Serbia and North Macedonia is similar.

Table 1. Summary of number of enterprises and relative value of SMEs compared with the EU28 average (for 2019). [1];

\begin{tabular}{|l|r|r|r|r|r|r|r|}
\hline \multirow{2}{*}{ Class size } & \multicolumn{7}{|c|}{ Number of Enterprises } \\
\cline { 2 - 8 } & \multicolumn{2}{|c|}{ Bulgaria } & \multicolumn{2}{|c|}{ Serbia } & North Macedonia & EU-28 \\
\cline { 2 - 8 } & Number & Share & Number & Share & Number & Share & Share \\
\hline Micro & 315410 & $91,80 \%$ & 294876 & $95,80 \%$ & 49372 & $89,90 \%$ & $\mathbf{9 3 \%}$ \\
\hline Small & 23471 & $6,80 \%$ & 10122 & $3,30 \%$ & 4576 & $8,30 \%$ & $\mathbf{5 , 9 0 \%}$ \\
\hline Medium & 4248 & $1,20 \%$ & 2288 & $0,70 \%$ & 797 & $1,50 \%$ & $\mathbf{0 , 9 0 \%}$ \\
\hline SMEs & 343129 & $99,80 \%$ & 307286 & $99,80 \%$ & 54745 & $99,70 \%$ & $99,8 \%$ \\
\hline Large & 623 & $0,20 \%$ & 521 & $0,20 \%$ & 151 & $0,30 \%$ & $\mathbf{0 , 2} \%$ \\
\hline Total & 343752 & $100,00 \%$ & 307807 & $100,00 \%$ & 54896 & $100 \%$ & $\mathbf{1 0 0 , 0 \%}$ \\
\hline \multicolumn{7}{|c|}{ Source: DIW Econ' 2019}
\end{tabular}

In the studied cases, we observe a similar trend, which refers to the number and ratio of SMEs and their participation in the structures of the Balkan countries' economies (Bulgaria, Serbia, and North Macedonia). The trend is also valid for the Union as a whole (EU-28). Notably, micro-enterprises form the largest relative share in all studied cases. Their most extensive presence is in Serbia, where over 95\% of all enterprises' are micro-organizations. For comparison, the author's team has identified the large organizations share, which in all cases form about $0.2 \%$ of the total number of enterprises. Only in North Macedonia, their share is $0.3 \%$, higher than the average Union's value.

Opportunities for providing employment is a continually exciting researchers question. Its relevance is becoming increasingly important, especially in the context of modernizing societies and new labor needs. In this sense, it is crucial to explore small and medium-sized enterprises' possibilities to ensure employment. In the European Union (EU-28), the SME sector provides $66 \%$ employment. This indicator is close to the Serbian economy, in which the SMEs sector engages $66.3 \%$ of the employed. In Bulgaria and Northern Macedonia, the 
number of people involved in employment in micro, small or medium enterprises is even higher. The values are $75.8 \%$ and $74.3 \%$, respectively. The large share is another reason that distinguishes the objective need for in-depth study of SMEs' development trend, its ability to provide employment, and its adaptability to the ever-changing requirements of the labor market and the related development of human resources. The SME sector seems to create high expectations of continuing to supply employment to the population. An additional finding in the investigated cases concerns large enterprises, although they are not a direct study object. In relative terms, large organizations are responsible for about 33\% at the EU level. However, it is notable that their share in the Balkan countries is below the Union average. The employment provided by large enterprises is about $24-25 \%$. Only Serbia is close to the Union average. We may find the reason in the well-developed industrial zones responsible for generating a significant share of employment. Regarding the number of SMEs in Bulgaria, the largest is their relative share in Services. This is typical of the whole territory of the Union and quite logical. The close share of SMEs in the field of Construction is the smallest. According to this indicator, Bulgaria significantly lags behind the Union average (6.1\% to $14.6 \%)$.

Table 2. Summary of number of employed people in SMEs compared with the EU28 average (for 2019). [1];

\begin{tabular}{|l|r|r|r|r|r|r|r|}
\hline \multirow{2}{*}{ Class size } & \multicolumn{7}{|c|}{ Number of Persons Employed } \\
\cline { 2 - 8 } & \multicolumn{2}{|c|}{ Bulgaria } & \multicolumn{2}{|c|}{ Serbia } & \multicolumn{1}{c|}{ North Macedonia } & \multicolumn{1}{c|}{ EU-28 } \\
\cline { 2 - 8 } & Number & \multicolumn{1}{|c|}{ Share } & Number & Share & Number & \multicolumn{1}{c|}{ Share } & \multicolumn{1}{c|}{ Share } \\
\hline Micro & 616012 & $30,60 \%$ & 442332 & $33,20 \%$ & 122402 & $31,60 \%$ & $\mathbf{2 9 , 7 \%}$ \\
\hline Small & 477693 & $23,70 \%$ & 203675 & $15,30 \%$ & 87555 & $22,60 \%$ & $\mathbf{2 0 , 1 0 \%}$ \\
\hline Medium & 432689 & $21,50 \%$ & 236836 & $17,80 \%$ & 78000 & $20,10 \%$ & $\mathbf{1 6 , 8 0 \%}$ \\
\hline SMEs & 1526394 & $75,80 \%$ & 882843 & $66,30 \%$ & 287957 & $74,30 \%$ & $\mathbf{6 6 , 6 \%}$ \\
\hline Large & 489587 & $24,20 \%$ & 447849 & $33,70 \%$ & 99950 & $25,70 \%$ & $\mathbf{3 3 , 4 \%}$ \\
\hline Total & 2015981 & $100,00 \%$ & 1330692 & $100,00 \%$ & 387907 & $100 \%$ & $\mathbf{1 0 0 , 0 \%}$ \\
\hline
\end{tabular}

Source: DIW Econ'2019

Comparing the data on the number of employees in different industries in SMEs' structure for Bulgaria and the EU-28, we can make some essential summaries. Although it engages the largest relative share in our country's economic system (42\%), the Services sector offered employment to $33 \%$ of the employed. In comparison, this value for the Union is close to $44 \%$. In terms of the number of employees, in the national economy, the service sector successfully competes with trade. The industries share an almost equal relative share of employees. The construction industry employs the smallest number of employees, both at the national and European level $(9.2 \%$ to $12.2 \%)$

Table 3. Summary of SMEs added value within Bulgaria, Serbia and North Macedonia compared with the EU28 average (for 2019). [1];

\begin{tabular}{|l|r|r|r|r|r|r|r|}
\hline \multirow{3}{*}{ Class size } & \multicolumn{7}{|c|}{ Value Added } \\
\cline { 2 - 8 } & \multicolumn{2}{|c|}{ Bulgaria } & \multicolumn{2}{|c|}{ Serbia } & \multicolumn{2}{c|}{ North Macedonia } & \multicolumn{1}{c|}{ EU-28 } \\
\cline { 2 - 8 } & Billion Eur & Share & Billion Eur & Share & Billion Eur & Share & \multicolumn{1}{c|}{ Share } \\
\hline Micro & 6,5 & $21,60 \%$ & 3,8 & $20,30 \%$ & 0,88 & $20,70 \%$ & $\mathbf{2 0 , 8 \%}$ \\
\hline Small & 7 & $23,20 \%$ & 2,9 & $15,40 \%$ & 0,95 & $22,40 \%$ & $\mathbf{1 7 , 6 0 \%}$ \\
\hline Medium & 6,1 & $20,50 \%$ & 3,8 & $19,90 \%$ & 0,86 & $20,30 \%$ & $\mathbf{1 8 , 0 0 \%}$ \\
\hline SMEs & 19,6 & $65,30 \%$ & 10,5 & $55,60 \%$ & 2,69 & $63,40 \%$ & $\mathbf{5 6 , 4 \%}$ \\
\hline Large & 10,4 & $34,70 \%$ & 8 & $44,40 \%$ & 1,6 & $36,60 \%$ & $\mathbf{4 3 , 6 \%}$ \\
\hline Total & 30 & $100,00 \%$ & 18,5 & $100,00 \%$ & 4,29 & $100 \%$ & $\mathbf{1 0 0 , 0 \%}$ \\
\hline
\end{tabular}

Source: DIW Econ'2019 
From the point of view of SMEs' added value at the Balkan countries' level and the European Union level, it is noteworthy that these organizations are responsible for more than half of the indicator's value. The fact is justified, given their strong relative presence in the structure of economies. We need to take that into account considering $0.2 \%-0.3 \%$ of the organizations in the national economies, represented by large enterprises, generate between 35 and $45 \%$ of value-added. Precisely because of this particular importance for developing economic sectors and providing an adequate response to the new challenges caused by dynamically evolving societies is developing a high-tech knowledge economy (Tsolov, G. 2019). The analysis requires us to compare the Bulgarian economy's performance in the context of the EU-28 averages. The graphs below visualize SMEs' dynamics and offer an overview of the development of different technology classes and knowledge-intensive SMEs.

To give depth to the study, we will focus on the Bulgarian case. The graph below shows the development of low-, medium- and high-tech and science-intensive sectors (2008-2017).

Figure 1. Number of low-, medium- and high-tech and science-intensive sectors SMEs in Bulgaria (2008 - 2020)

Number of SMEs in Bulgaria

(Index: 2008=100, estimates as from 2017 onwards)

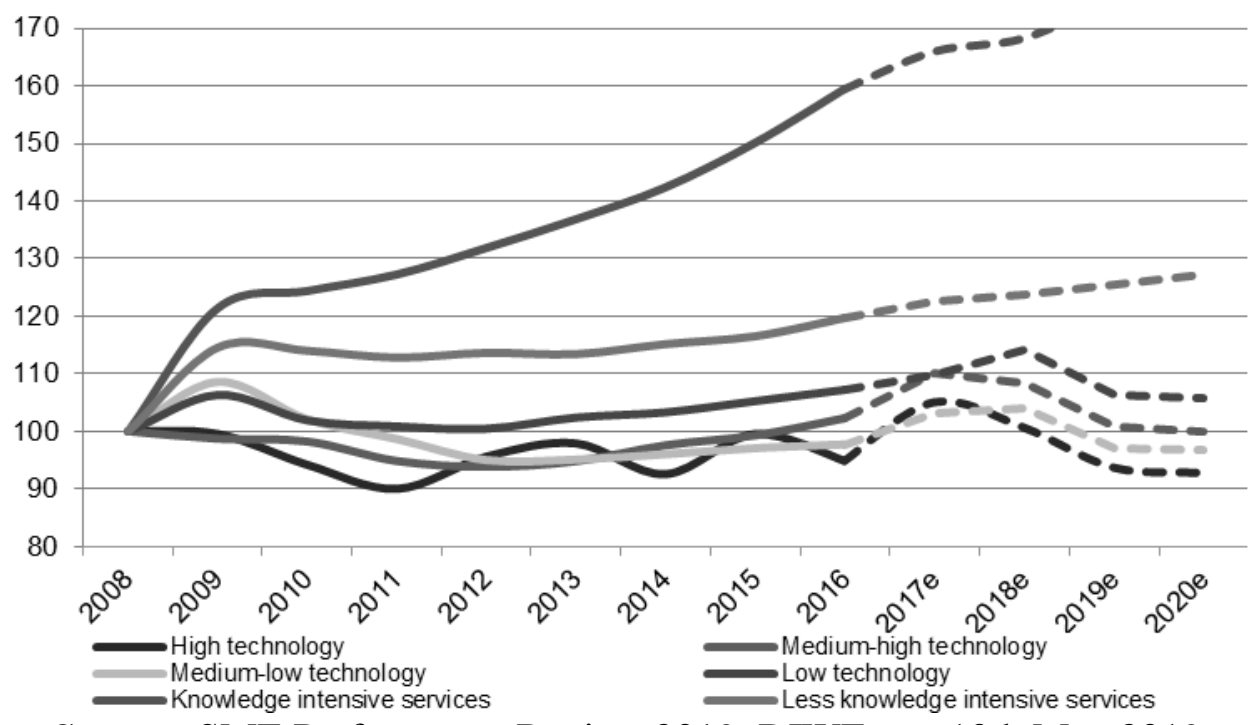

Source: SME Performance Review 2019, DIWEcon, 10th May 2019

For the period 2008-2016 and the forecast 2017-2020, Bulgaria reports excellent results regarding the dynamic increase in the number of Knowledge-intensive services, as their number almost doubles. However, there is no progress or expansion in their number concerning high-tech industries, but even a decrease, compared to the indicators achieved in 2008. Bulgaria should realize a large part of its untapped potential in terms of high technologies. In catching up with development, technologies should be dynamically recognized and integrated into the Bulgarian regions' economic activities to optimize production. However, there are many reasons why this does not happen, and Bulgarian SMEs face several challenges in integrating high-tech industries. On the one hand, this is the still tricky access to funding (including poor understanding of procedures, lack of transparency, and publicity); on the other hand, the increasingly topical issues related to human resources and capital (Tanakov, N. 2019).

For comparison, we also apply the graph of identical industries and the values for the EU-28. We see that the development is analogous. Here we can think in two directions. On the one hand, opportunities should be sought for better integration of global technological innovations 
in the field of economic sectors, and on the other hand, to design and program new concepts for the development of territories expressed through the prism of Intelligent Regional Specialization.

Figure 2. Dynamics of the Number of SMEs in EU-28 (technology and knowledge) 2008 2020

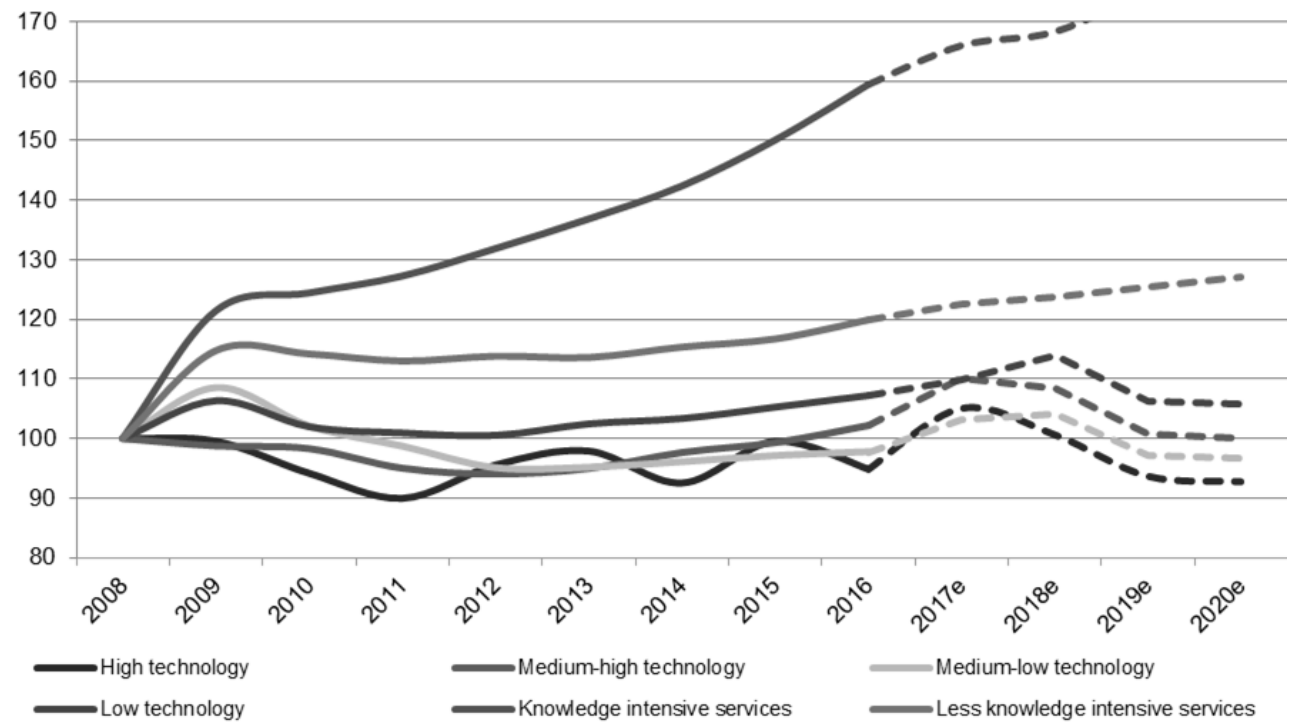

Source: SME Performance Review 2019, DIWEcon, 10th May 2019

Regarding the share of fast-growing SMEs, in 2016, a balanced structure of development, against European enterprises' background, is impressive. In the general case, the ratio Bulgaria: EU-28 is $11.2 \%: 10.7 \%$. According to the specific indicator, Bulgarian SMEs are ahead of the average for the Union in terms of growth. Outpacing values are also observed in the areas of Transportation and storage, Manufacturing, Real estate activities, Construction, Wholesale and retail trade, repair of motor vehicles and motorcycles.

It is important to note that the rapid growth of information and communication enterprises' share continues. Thus, the percentage of IT companies is growing most dynamically. This, of course, is a very logical response to the current trends in modern societies' development. In this sense, in 2016, their share in Bulgaria increased by $13.7 \%$, and for the Union by $16.5 \%$. The increase in employees in the industry is happening at a slightly more moderate pace. According to data for 2018, they increase by $9 \%$ annually to 30.1 thousand, and in 2019 increase by $10 \%$ to 34.1 thousand people. Historically, within seven years, employees in software companies have doubled in number. This should keep relevant to the eternal issue of staff shortages in the IT field.

Although at the EU-28 level, 49.5\% of SMEs have undertaken some form of innovation, the share of innovative SMEs varies considerably from one Member State to another. In 13 Member States, over 50\% of SMEs in 2014-2016 were innovators. On the other hand, 7 Member States, incl. Bulgaria has taken the form of innovation in less than 1/3 of SMEs. Within the EU-28, the gap between innovative large enterprises and innovative SMEs is particularly large in several Central European countries, including Bulgaria.

According to the European Commission's report, the main barriers reasons for the development of innovation for SMEs in Bulgaria are: Lack of cooperation partners; Lack of external 
financing (credit or private capital); Difficulties in obtaining public subsidies; High competition; Uncertain market demand; Lack of qualified employees in the enterprise; 'Lack of internal finance' and 'High costs'.

Most innovative SMEs believe that each barrier is more important than large enterprises for all the factors considered. Innovative SMEs typically face a much more comprehensive range of challenges than innovative large enterprises. It is more difficult for SMEs to obtain funding for their innovations, whether from external, internal, or government sources. SMEs are less likely to have qualified employees to innovate and find it more challenging to find cooperation partners. Some factors are particularly important for SMEs. For example, 6\% of large enterprises say that the "lack of external financing" is essential to hamper innovation efforts, compared to $12.9 \%$ of SMEs. Besides, $14.4 \%$ of SMEs cite "high competition" as a significant barrier compared to $7.6 \%$ of large companies. These differences reflect the SMEs' specific market context, which seems less favorable for innovation at the aggregate level. In general, SMEs seem to find it relatively more difficult to increase and maintain their innovation activity.

In January 2017, the Commission carried out a comprehensive assessment of Bulgaria's progress over the last ten years since the establishment of the Cooperation and Verification Mechanism (SME) in 2007.

Based on the long-term perspective and significant progress, the Commission has outlined 17 key recommendations, the implementation of which would lead to the termination of the SME process, in line with President Juncker's goal of completing the SME process by the end of this Commission's term. Therefore, the recommendations made in January 2017 are considered sufficient for SMEs' closure unless changes occur that could lead to a clear reversal of progress. It was also stressed that the process's pace would depend on how quickly Bulgaria will implement the recommendations irreversibly (Vasileva, E. 2018). In particular, the recommendations focused on the Bulgarian authorities' accountability requirements and on the introduction of internal guarantees to ensure the irreversibility of the results, i.e. to prove that the implementation of ongoing projects will continue, even without SMEs. As the Council emphasized, SMEs' performance will end when each of the six indicators applicable to Bulgaria is satisfactorily met (Bulgaria's Progress Report 2018. [COM(2018)850]).

\section{INTELLIGENT REGIONAL SPECIALIZATION - THE MODERN DIMENSION OF SECTORAL CONCENTRATION}

What is smart specialization [3]? Smart specialization is a strategic approach to economic development through targeted support for research and innovation (R\&D). This will be the basis for Structural Funds investments in R\&D, as part of the contribution of Cohesion Policy to achieving the long-term goals for growth and jobs of the Europe 2020 Strategy (Nikolov, G., Vasileva, E. 2018). More generally, smart specialization involves a process of developing a vision, identifying competitive advantages, setting strategic priorities, and using smart policies to maximize development potential based on the knowledge of each region, whether weak, strong, high- or low-tech (Nikolov, G. 2019). The Innovative Intelligence Specialization Strategy (ISIS) is generally a strategic document for changing Bulgaria's policy and overcoming the socio-economic challenges. It is a means to improve the competitiveness of the economy, both in Bulgaria and in the EU. Smart specialization is such for two reasons: it sets the main priorities for both politics and industry; it considers global trends, stimulating businesses to reach their true potential. It provides an opportunity to build on the strategic advantages of the given territories, which implies a clear communication policy, active 
participation of stakeholders, a high degree of integration, and connection with international guidelines and programs.

Smart specialization strategies contribute to the Europe 2020 goals of smart, sustainable, and inclusive growth by strengthening the EU's regional and national research and innovation potential.

Smart specialization is a concept of innovation policy that aims to stimulate regional innovation, contributing to growth and prosperity, helping and enabling regions to focus on their strengths. Smart specialization is based on partnerships between businesses, public entities, and knowledge institutions (e.g., the Academy).

Defining the smart specialization strategy established by Regulation (EU) № 1303/2013 of the European Parliament and the Council defines it as: "Smart specialization strategy" means national or regional innovation strategies that set priorities to build competitiveness advantage. The SS develops and compares research and innovation's strengths with business needs to achieve a coherent solution to emerging opportunities and market developments. It avoids duplication and fragmentation of efforts; The smart specialization strategy can take the form of (or be included in) a national or regional strategic framework for research and innovation. The Smart Specialization Platform (S3 Platform) provides information, methodologies, expertise, and advice to national and local policies and promotes mutual learning and transnational cooperation, and contributes to the academic debate on the concept of smart specialization.

The smart specialization strategy must prioritize areas, sectors, and economic activities where regions or countries have a competitive advantage or have the potential to generate knowledge growth and lead to the economic transformation needed to address the main and most pressing challenges facing society, and the natural and built environment. The number and nature of these priorities will vary from region to region.

Such an approach requires keeping in mind that when designing the Smart Specialization Strategy, priorities need to be identified that can be changed or modified when the availability of updated information/analyzes recommends it. Priorities could be formulated in terms of areas of knowledge or activities (not only science-based but also social, cultural, and creative), subsystems within a sector, corresponding to specific market niches, clusters, technologies, or the scope of application of technologies for specific societal and environmental challenges or the health and security of citizens (e.g., ICT for active aging, mobility solutions to reduce traffic congestion, innovative material solutions for eco-building, etc.).

While some regions or countries may prioritize one or more key technological innovations, others will focus on such technologies' applications to specific goals or specific areas. Social, organizational, market, and service innovation or practice-based innovation play as important a role in the Smart Specialization Strategy as research-based technological innovation. This is especially important for regions with a relatively weaker technical and scientific basis.

The smart specialization strategy includes radical innovation and the use of niches through design in traditional areas, the development and implementation of new business or organizational models, and the adaptation/use of invention stemming from knowledge and experience in these areas. Horizontal measures will complement the priority choice of districts, sectors, or specific economic activities. They aim to realize adequate framework conditions for 
entrepreneurship, supporting the work of all types of companies both on the domestic and international markets and the development of inter-company, inter-cluster, and cross-border cooperation.

\section{CONCLUSION}

Intelligent regional specialization is called to work and stimulate the best of the territory, thus improving living standards, socio-economic and regional development, and increasing regional competitiveness. It is built based on platform thinking, which aims to improve the investment climate in the regions, promote entrepreneurship, and the development of high-tech industries and the knowledge economy.

The main engine of such platform thinking is innovation and the ability to generate, adapt, and integrate innovations. Based on the analysis, it is clear that Bulgarian SMEs still face several difficulties in innovation. It is not well implemented and recognized as a priority area for development by small and medium businesses. Despite the many programs aimed at supporting innovative SMEs, the share of SMEs undertaking innovative activities has not changed significantly since the beginning of 2000. Bulgaria traditionally maintains its place among the old non-innovators. However, this is valid with some reservations. The amplitude between SMEs' innovation activity and the corporations, which have the role of the core of the innovative development of our country, is significant.

The analysis of the degree of innovation and non-innovation among SMEs (and large enterprises) showed that our country's general innovation climate is an important driver for the spread of innovation activity among SMEs and large enterprises. Many of the existing programs address a wide range of issues and challenges that have been identified by innovative and non-innovative SMEs. Stakeholders have suggested several additional actions that could increase SMEs' innovation rate in the EU. However, there are large differences across the EU concerning the frequency of innovative SMEs among the SME population. The scope and type of problems they face and the level of state support for R\&D in SMEs vary.

The regional specialization and especially its modern intelligent concepts contain several opportunities for the Bulgarian regions. Proper recognition of priorities would generate added value, economic growth, and development. The accurate and timely orientation of regional development policies towards a small number, concretely and clearly defined regional priorities with significant and possible for realization potential, based on the specific territorial reality, is the key to bringing the Bulgarian regions to the European and the world economic scene.

\section{Notes:}

[1] The data presented in the table are forecasts for 2018, prepared by DIW Econ, based on data from 2008-16 from the Structural Database for Business Statistics (Eurostat). The data cover the "non-financial business economy", including industry, construction, trade, and services. The following definitions of the size class apply micro-firms (0-9 employees), small companies (10-49 employees), medium-sized companies (50-249 employees). The advantage of using Eurostat data is that the statistics are harmonized and comparable between countries. The disadvantage is that for some countries, the data may differ from those published by national authorities; 
[2] Alfred Kristaler (1893-1969) was a German geographer, the founder of the rational theory of the hierarchy of settlements. According to his main work, The Central Cities of Southern Germany, people organize their settlement network to make the most efficient use of the region's natural resources and localization advantages.

[3] Platform for intelligent specialization of the EC. http://s3platform.jrc.ec.europa.eu.

\section{REFERENCES}

Khalachev, V. (2018) 'Analiz na razvitieto na MSP v Bŭlgariya prez 2018 godina', https://ubclubs.eu/, posledno obnovena: 28.12.2018, accessed: 04.08.2020

Aktualni danni za MSP (2014-2018), Ministerstvo na ikonomikata na Republika Bŭlgariya

Doklad za napredŭka na Bŭlgariya za 2018 g. [COM(2018)850]

Nikolov, G., Vasileva, E. (2018) Usŭvŭrshenstvane na politikite za ikonomicheskoto razvitie na regionite. Natsionalna nauchna konferentsiya: Regionalna ikonomika i ustořchivo razvitie,tom 1, izd. Nauka i ikonomika, r.78-85. ISBN 978-954-21-0956-3Blaug, M. (1992). The methodology of economics, or, How economists explain. Cambridge University Press. p. 190. ISBN 978-0-521-43678-6.

Leontief, W. (1953). "Domestic Production and Foreign Trade; The American Capital Position Re-Examined". Proceedings of the American Philosophical Society. 97 (4): 332-349. JSTOR 3149288

McCann, P., \& Ortega-Argilés, R. (2015b). Smart specialisation: Results-oriented policies and the use of results indicators with specific reference to entrepreneurship and SMEs policies. Discussion Paper Prepared for the Smartspec Framework 7 Project.

McCann, P., \& Ortega-Argilés, R. (2013b). Transforming European regional policy: A resultsdriven agenda and smart specialisation. Oxford Review of Economic Policy, 29(2), 405431.

Nikolov, G., Lyubomirova, V., Suryanto, T. (2019) "Building an integrated regional approach in the new programming period 2021-2027". III International Conference "Regional development and cross-border cooperation". Serbia, Pirot 2019. ISBN 978-86-9004972-1

Nikolov, G. (2019) Innovations as a factor for regional growth. "Mezhdunarodnata nauchna konferentsiya, Tendentsii v upravlenieto na Regionalnoto razvitie i sigurnostta. ISBN 978-619-232-265-6

Ricardo, D. (1817), On the Principles of Political Economy and Taxation (1 ed.), London: John Murray, retrieved 2020-08-07 via Google Books

Smith, Adam (1789). An Inquiry into the Nature and Causes of the Wealth of Nations. 1 (5 ed.). London: A. Strahan; T. Cadell.

Tanakov, N., Kazakova, M. (2019) Impact of human resources on the development of the regions. "II International Scientific Conference - Regional development and cross-border cooperation, pp 513-521". Serbia, Pirot. ISBN 978-86-900497-1-4

Thünen, Johann Heinrich von. (1826) Der isolierte Staat in Beziehung auf Landwirtschaft und Nationalökonomie, Akademie-Verlag, 1990, retrieved 2020-08-07 via Google Books

Tsolov, G., Vasileva, E. (2019) European concept of collaborative economy, XXIV Međunarodni naučni skup Regionalni razvoj i demografski tokovi zemalja jugoistočne Evrope, Nis, Serbia, ISBN 978-86-6139-178-1

Vasileva, E. (2018) Genesis and Possibilities for Overcoming the Regional Disparities in Bulgaria Development. International conference proceeding: Regionalni razvoj i demografski tokovi, University of Nish, Facility of Economics, p.225-257. Nis, Serbia. ISBN 978-86-6139-155-2 